\title{
Contrast Sensitivity Function of the Albino Rat Determined Electrophysiologically
}

\author{
Pilar Herreros de Tejada* and Carmen Muñoz Tedó* \\ Complutense Unjversity of Madrid
}

\begin{abstract}
Albinism alters the neural projections of the visual system. The authors wondered how this would affect visual function in rodents. They had previously shown that it doesn't alter the luminance threshold. They now explore visual acuity in the albino rat. In this work, they describe its contrast sensitivity function (CSF), as determined electrophysiologically. They recorded cortical visual evoked potentials (VEP) on six albino rats, stimulated by sinusoidal contrast reversal gratings. The curve showed the same characteristics that this function has in other mammals. Compared with the pigmented rat, the albino reached lower sensitivity values and showed a loss of sensitivity at high spatial frequencies. The estimated cut-off was $0.48 \mathrm{c}^{\circ}$, that is, $0.72 \mathrm{log}$ units below the estimated cut-off for the pigmented rat under similar experimental conditions. VEP and behavioral cut-off were very close, the VEP estimation being slightly higher than the behavioral one. Key words: visual acuity, albinism, rat, VEP
\end{abstract}

El albinismo altera las proyecciones neurales del sistema visual. Nos planteamos qué efecto puede tener sobre la función visual en roedores. En trabajos previos hemos mostrado que el albinismo no altera el umbral de luminancia. En el presente trabajo hemos explorado la agudeza visual de la rata ałbina. Describimos la función de sensibilidad al contraste (FSC) determinada electrofisiológicamente mediante registros de potenciales evocados visuales (PEV) en seis ratas albinas que eran estimuladas por enrejados sinusoidales. La curva presenta las mismas características definitorias que esta función tiene en otros mamíferos. Comparada con la rata pigmentada, la rata albina alcanza unos valores de sensibilidad más bajos y muestra una pérdida de la sensibilidad para las frecuencias espaciales altas. La frecuencia de corte estimada es $0.48 \mathrm{c} /$, es decir, 0.72 unidades logarítmicas más baja que la frecuencia de corte estimada para la rata pigmentada en condiciones experimentales similares. Las frecuencias de corte estimadas conductualmente o mediante registros de PEV están muy próximas, siendo la estimación electrofisiológica un poco más alta que la conductual.

Palabras clave: agudeza visual, albinismo, rata, PEV

The authors wish to thank C.A. Heywood for his help with this work.

* Correspondence concerning this article should be addressed to the authors, Departamento de Psicobiología, Facultad de Psicología. Campus de Somosaguas. 28223-Madrid (Spain). E-mail; pspsc03@sis.ucm.es, cmt@sis.ucm.es 
Albino rats are one of the most common subjects in research. Both visual and nonvisual experiments are carried out with these animals. The anomalous visual pathways produced by albinism are already well known. Many papers describe the misrouted fibers of the ipsilateral projections (Drager \& Olsen, 1980; Guillery, 1974; Lund, 1965) and link this to the loss of pigmentation (LaVail, Nixon, \& Sidman, 1978; Sanderson, Guillery, \& Shackelford, 1974). However, little is known about the effect of the anomalous pathways on the visual sensitivity of albino rodents.

In the past few years, controversy has arisen about a possible night blindness in albino rodents (Balkema, 1988; Hayes \& Balkema 1993). We were able to show that this is not the case either for mouse or for rat (Herreros de Tejada, Green, \& Glover, 1994; Muñoz Tedó, Herreros de Tejada, \& Green, 1994). Electroretinogram (ERG) and visual evoked potential (VEP) recordings, as well as behavioral measurements, gave absolute threshold values which were similar for albino and pigmented subjects in both species. We can now state that albinism does not reduce sensitivity to light.

However, what about the visual acuity of albino animals? How well do they see details? Normal pigmented rats and mice show poor visual acuity compared with cats and primates. The estimated resolution limit is around $1.2 \mathrm{c} /$ for pigmented rats and around $0.6 \mathrm{c} /{ }^{\circ}$ for pigmented mice. These values are about 10 and 60 times lower than those of visual acuity for cats and humans, respectively. Very few studies have been carried out on albino rats. Birch and Jacobs (1979) measured the contrast sensitivity function (CSF) behaviorally on two animals. They found a general decrease of the sensitivity to spatial contrast in the albino subjects, compared to pigmented ones, as well as a loss of sensitivity at high spatial frequencies. Neither albino nor pigmented rats showed the attenuation of sensitivity at low spatial frequencies that is characteristic of the CSF in other mammals. Subsequent behavioral work in the laboratory (Muñoz Tedó, Herreros de Tejada, \& Cañavate, 1992) has allowed completion of the characterization of the CSF of the albino rat. These authors confirmed a resolution limit around $0.35 \mathrm{c} /$, but also observed an attenuation of sensitivity at low spatial frequencies of the albino rat and, therefore, the characteristics of the CSF in albino rats are similar to those of other mammal species.

Other laboratories have tried to measure the contrast sensitivity of the albino rat electrophysiologically. An electrophysiological characterization of the CSF is a very powerful tool in research because it allows researchers to determine the impact of various manipulations (i.e pharmacological, genetic, etc.) on visual function, avoiding difficult and time-consuming behavioral measurements. This type of electrophysiological work has already been carried out on pigmented rats by Silveira and co-workers with VEP recordings (Silveira, Heywood, \& Cowey, 1987). However, attempts to measure the CSF on albino animals with VEP recordings (Boyes \& Dyer, 1983) were not so successful because they found albino VEP responses to be smaller in amplitude and less well-defined than those of the hooded rats. These authors also reported that the albino waveform could not be discriminated from noise at spatial frequencies between 0.2 and $0.44 \mathrm{cl}$.

In this work, we carried out a systematic study on the albino rat's sensitivity to spatial contrast, as determined electrophysiologically by VEP recordings. We described the complete CSF of the albino rat and compared our electrophysiological results with previous behavioral ones. The responses were clearly observable at the highest spatial frequency used $(0.33$ $\mathrm{c} /{ }^{\circ}$ ) and the estimated cut-off was $0.48 \mathrm{c}^{\circ}$.

\section{Method}

\section{Subjects}

Six Sprague-Dawley female albino rats were used. The animals were about 9 months old and weighed between $320-$ $340 \mathrm{~g}$.

\section{Materials and Procedure}

Materials and procedure are basically the same as used by Silveira et al. (1987) and Heywood, Silveira, and Cowey (1988) for the determination of the CSF in the pigmented rat. All procedures were in compliance with the APA guidelines for the Use of Animals in Research.

Animals were anesthetized with fentanyl/fluanisone (Hypnorm, $0.6 \mathrm{ml} / \mathrm{kg}$ im) and diazepam (Valium, $5 \mathrm{mg} / \mathrm{kg}$ ip) and then mounted on a stereotaxic device. Supplementary doses were administered when needed throughout the recording session of about 10 hrs. A craniotomy was performed on the right hemisphere. Cortical evoked responses were recorded via a silver/silver chloride epidural electrode of $1 \mathrm{~mm}$ tip diameter placed in area 17 , in the region of the central binocular visual field's representation (Montero, Rojas, \& Torrealba, 1973). Physiological signals were amplified $10.000 \mathrm{x}$ and low frequency filtered at $0.1 \mathrm{~Hz}$ in a differential preamplifier (Digitimer, NL 104). They were filtered additionally in an NL125 for frequencies below $0.5 \mathrm{~Hz}$ and above $100 \mathrm{~Hz}$ (40 dB/decade attenuation). An additional notch filter ( $50 \mathrm{~dB}$ attenuation) was used to reject main noise.

Stimuli consisted of approximations to horizontal sine wave gratings of variable spatial frequency $(0.04,0.08,0.10$, $0.17,0.25$, and $0.33 \mathrm{c} /$ ) and Michelson contrast $(0.88,0.7$, $0.44,0.21$, and 0.086 for all the frequencies studied except for the frequency of $0.33 \mathrm{c}^{\circ}$, whose contrast values were 0.88 , $0.8,0.7,0.6$, and 0.44$)$. The mean luminance of the display was kept constant at $0.23 \mathrm{~cd} / \mathrm{m}^{2}$ and the grating contrastreversed with a $1 \mathrm{~Hz}$ square-wave signal. The screen was placed at a distance of $28.5 \mathrm{~cm}$ in front of the animal and centered in the midline, $10 \mathrm{~cm}$ above the horizontal plane and 
subtended $40^{\circ}$ wide by $26^{\circ}$ high. Series of stimuli were presented in a predetermined but otherwise random order, interleaved with a standard stimulus $(0.08 \mathrm{c} /$ and 0.88 contrast).

The continuous or triggered recordings were displayed on a storage oscilloscope (Advance, OS 2200A). A microcomputer system ( $380 Z$, Research Machines) averaged the responses, taking $500 \mathrm{samples} / \mathrm{s}$. The number of contrast reversals contributing to each VEP varied from 256 to 1024 according to the signal/noise level. The averaged VEPs were analyzed by computer into their sinusoidal components by a Fast Fourier Analysis Program. The DC component was discarded and the first ten even harmonics re-synthesized to a compound waveform by the inverse transform. Peak amplitude was measured in the re-synthesized waveform and this value was considered the absolute value for each pattern.

The recording sessions were always initiated with the presentation of the standard pattern in series of 256 contrast reversals. Usually, the responses were clear and stable after two or three series and then, the next series of 256 presentations were the first data analyzed. After that, a spatial frequency was chosen and presented with the maximum contrast used for that frequency. For example, if the chosen frequency was $0.1 \mathrm{c} \%$ a series of 256 contrast-reversed presentations of that pattern with 0.88 contrast was recorded. Immediately afterwards, another series of the standard pattern was recorded. Next, the contrast of the $0.1 \mathrm{c} / \%$ pattern was reduced to 0.7 and a new series of 256 contrast-reversed presentations was recorded. Another series of standard pattern presentations followed and then, the contrast of the $0.1 \mathrm{c}^{\mathrm{D}}$ was again reduced, to 0.6. As the contrast for each frequency was reduced, a higher number of presentations was required. The maximum number of presentations used was 1024. After the series of a frequency with the 5 different contrast levels was recorded, a new frequency was chosen, and a similar protocol followed.

The mean response to each test stimulus $(R)$ was always compared with the mean response to the standard pattern that immediately preceded (SP1) and followed (SP2) the presentation of the test stimulus with the formula (R/SP1 + $\mathrm{R} / \mathrm{SP} 2) / 2$. This value was considered the stimulus' relative value and took into account the animals physiological conditions and the changes in the standard pattern throughout the day. In order to calculate the contrast thresholds for each spatial frequency we plotted a graph relating the logarithm of the grating's contrast to the relative amplitude of the evoked response to the standard pattern. The experimental points were fitted with linear regressions calculated by the least square method.

\section{Results}

\section{VEP Characteristics}

The VEP recorded on the area 17 of the albino rat showed similar wave form characteristics to those described for the hooded rat (Silveira ot al, 1987), although the amplitude values were lower. The VEP wave form consisted of an early positive (PI) and a late negative (NI) component. Both components were very reliable, the positive being consistently larger and sharper than the negative.

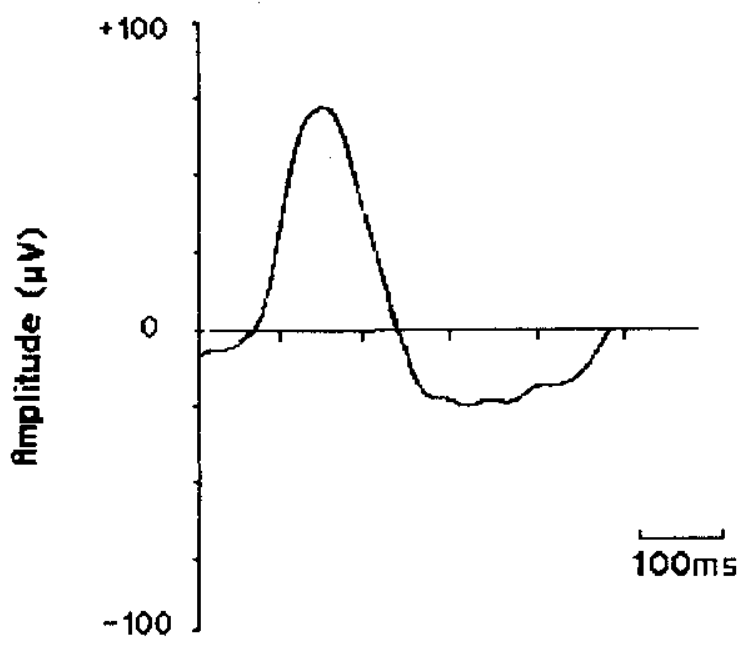

Figure 1. Example of an average VEP recorded when the animal was being stimulated by the standard pattern (256 presentations).

Figure 1 shows the average VEP of a single animal, recorded when stimulated by the standard pattern. This pattern, as previously mentioned, corresponds to a grating of $0.08 \mathrm{cl}^{\circ}$, contrast-reversed at $1 \mathrm{~Hz}$ and a contrast level of 0.88 . The mean absolute value of the VEP amplitude for the standard pattern, considering the data from all six animals, was $73 \mathrm{mV}$. In general, when spatial frequency was kept constant and contrast varied between 0.88 and 0.086 , response amplitude increased with contrast; on the other hand, when contrast was kept constant at 0.88 and spatial frequency varied between 0.08 and $0.33 \mathrm{c}^{\circ}$, response amplitude decreased with frequency.

\section{Contrast Thresholds}

To calculate thresholds, a graph was plotted for each spatial frequency, relating the logarithm of the contrast of the grating to the relative amplitude values. Points were fitted with linear regressions calculated by the least square method. This is represented in Figure 2, where single points correspond to the average data of six albino rats. The correlations in all cases are high. As other authors described (Harnois, Bodis-Wollner, \& Onofrj, 1984; Silveira et al., 1987), sometimes two limbs may be observed in the relationship between contrast and amplitude. Considering 

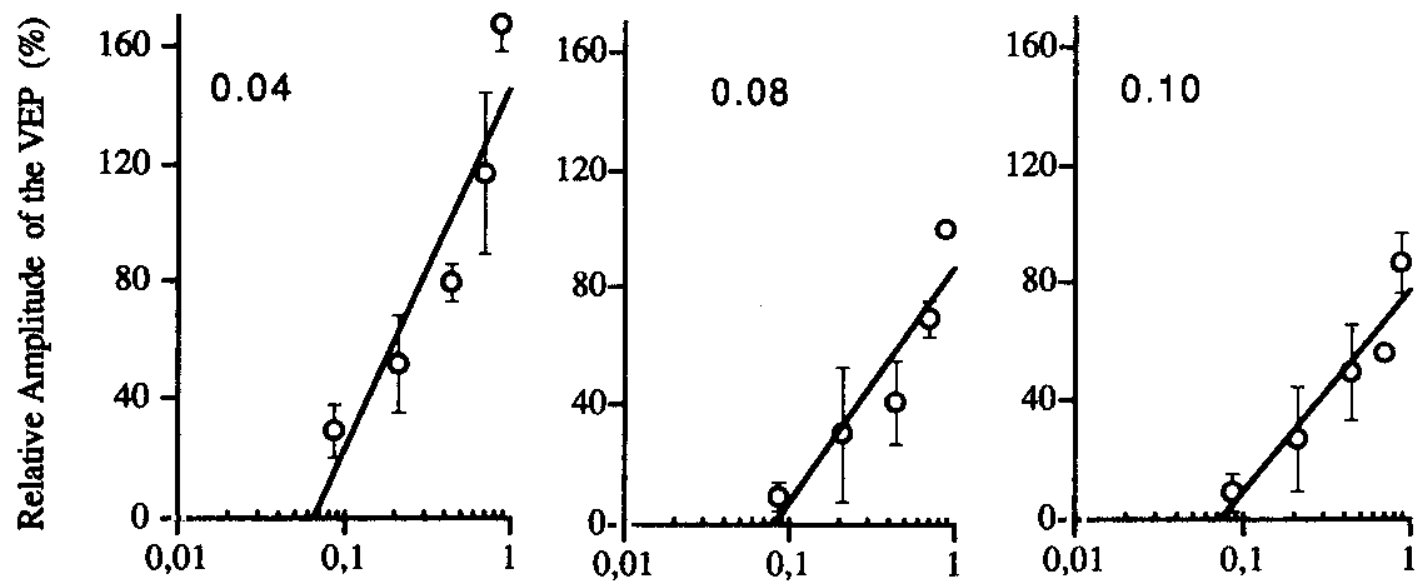

contrast
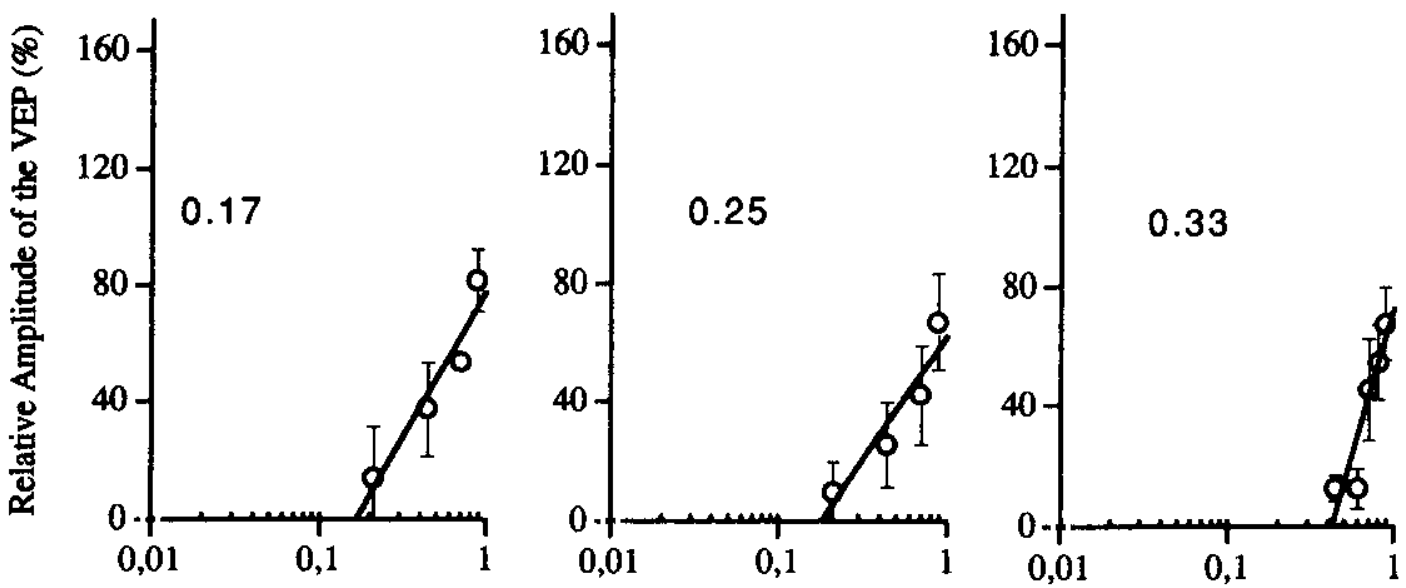

contrast

Figure 2. Relationship between contrast and VEP relative amplitude for various spatial frequencies. Each point corresponds to the average data of the group. Bars indicate the standard error of the means. Linear regressions fitted to experimental points by the least square method.

that, in the present case, excluding the highest points of each graph would not significantly improve the correlations, all contrast levels were considered when determining the threshold values.

Contrast thresholds were determined by extrapolating the linear regressions from Figure 2 to zero amplitude. Thresholds decreased progressively from 0.1 to $0.33 \mathrm{c}^{\circ}$, smoothly between 0.1 and $0.25 \mathrm{c}^{\circ}$, and with a strong drop between 0.25 and $0.33 \mathrm{c} f^{\circ}$. The threshold at $0.08 \mathrm{c} l^{\circ}$ was slightly higher than at $0.1 \mathrm{c} /$. The lowest threshold appeared at $0.04 \mathrm{cl}$. Thresholds were obtained from the average data of the group.

\section{Contrast Sensitivity Function}

Contrast sensitivity at threshold was plotted by taking the inverse of the contrast threshold values previously obtained from Figure 2. Double logarithmic plots of contrast sensitivity and spatial frequency are shown in Figure 3. The points were fitted with an exponential regression by the least square method. The curve was extrapolated to unitary contrast sensitivity to provide an estimate of the spatial frequency cut-off. The estimated cut-off for the group was $0.48 \mathrm{c} l^{\circ}$. The maximum sensitivity value was reached at $0.04 \mathrm{c} /$, smoothly decreased till $0.1 \mathrm{c}^{\circ}$, and more abruptly at higher spatial frequencies. 


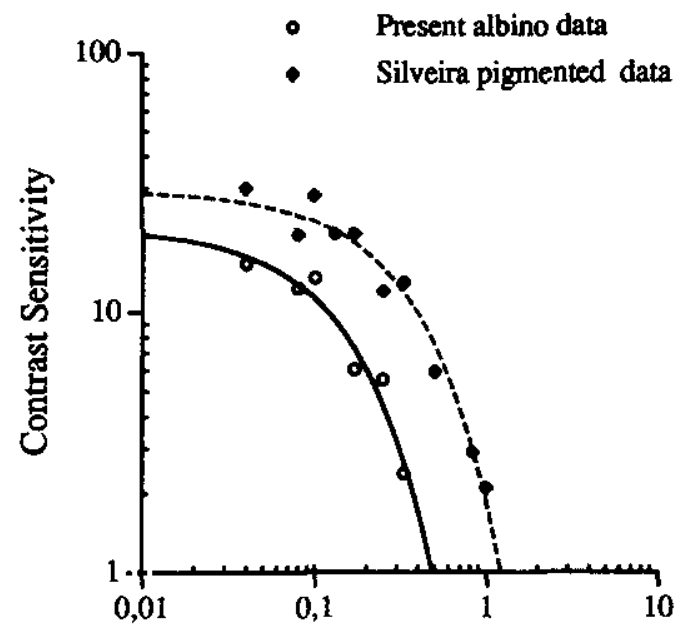

Spatial frequency (cycles/degree)

Figure 3. Contrast sensitivity functions of the albino and pigmented rat determined electrophysiologically by VEP recordings. Open symbols and solid lines correspond to data obtained in this study for the albino rat. The extrapolated albino cut-off was $0.48 \mathrm{c} /$. Closed symbols and dashed lines represent the pigmented rat CSF obtained by Silveira et ai. (1987).

\section{Discussion}

\section{VEP Characteristics}

The VEPs obtained in this work on the albino rat (Sprague-Dawley) show the same components (P1, N1) described by Silveira et al. (1987) in the hooded rat. There are just a few electrophysiological studies on albino rats using gratings as stimulus patterns and some authors report comparatively noisier or unreliable VEP responses than the recordings on pigmented subjects (Boyes \& Dyer, 1983). It is possible that the difference obtained by other authors in the VEPs' shape and sharpness between albino and pigmented rats could be due to the position of the electrodes. As mentioned above, the electrode's position in this study corresponds to the cortical representation of the intersection between the vertical and horizontal meridians within the binocular visual field. Because of the anomalous visual projections in albino subjects (Drager \& Olsen, 1980; Guillery, 1974; Lund, 1965), a slight variation of the electrode's location could affect the results obtained with these animals, even though the responses of pigmented subjects would not be significantly altered. Nonetheless, other methodological variables, such as the anesthetic conditions, could also explain the differences.

Although VEP components are similar both in albino and pigmented rats, the VEP amplitude of the former is considerably smaller. In the work of Silveira et al. (1987), the amplitude of the response, recorded when the animal was stimulated by the standard pattern, was approximately $150 \mathrm{mV}$. In the present work, the mean amplitude of the responses of albino rats is $73 \mathrm{mV}$ when stimulated by such a pattern. Similar differences in amplitude can be observed with the other grating patterns and may be related to the albinism anomaly, as well as to the difference in the patterns' luminance. The luminance of the patterns in our work is 1.8 $\log$ units lower than that used by the Silveira group; this difference does not allow a strict comparison between the VEP amplitude of our albino and their hooded rats, even if other measures, such as the contrast thresholds, are not affected and, therefore, can be compared.

Dyer and Swartzwelder (1978) have already described the difference between the VEP amplitude of albino and pigmented rats, using flashes of several white light intensities as stimuli, but their data differ from ours. In these authors' work, the Sprague-Dawley albino rat showed VEPs which were larger in amplitude than those for the Long-Evans hooded rats. The response amplitudes obtained in the present work in albino (Sprague-Dawley) rats are smaller than those of the VEPs presented by Silveira et al. (1987) for pigmented (Lister hooded) subjects. The difference in the results using different strains may be due to the above-mentioned difference in the luminance pattern which prevents us from comparing the VEP amplitude obtained in this work with the VEP amplitude values presented by Silveira and co-workers. Another possible explanation for the strain difference could be the stimuli used (flashes in Dyer \& Swartzwelder; gratings in Silveira et al. and in the present study). Finally, it might also be due to other variables, such as a difference in the responses of several pigmented strains or the diameter of the dilated pupil.

\section{Contrast Thresholds and Contrast Sensitivity Function (CSF)}

Two segments are generally described in the function relating VEP amplitude and log contrast, the slope of the second one being steeper (Harnois et al., 1984; Silveira et al., 1987). Authors tend to exclude the highest contrast points if this criterion increases the correlation coefficient, and calculate the contrast threshold using only the points corresponding to lower contrasts. In our experiment, as mentioned, the correlations did not improve when we excluded the highest contrast values and, therefore, we have included them in our analysis. We extrapolated these functions to zero amplitude, and the sensitivity values for each frequency are the inverse of the thresholds obtained by this method.

In our study, the maximum sensitivity value is reached at the lowest spatial frequency used: $0.04 \mathrm{c}^{\circ}$. This result might be somewhat surprising since the CSF in other species has been described as showing an attenuation at low spatial frequencies. 
However, our present results are in agreement with those previous results. Laboratory research has already been able to show that the performance detecting the spatial frequency of $0.1 \mathrm{c} /$ is much better than the performance detecting 0.08 c/ (Muñoz Tedó et al., 1992). In the present study, we consider the sensitivity peak to be at $0.1 \mathrm{c} /{ }^{\circ}$. At this point, sensitivity decreases with spatial frequencies lower than the peak (see $0.08 \mathrm{c} /$ ). The extremely small difference in sensitivity between 0.08 and $0.1 \mathrm{c} /$ observed in Figure 3 was also observed in each individual animal. That is, not only the average data in Figure 3 reflect the reduction of sensitivity at $0.08 \mathrm{c} /$ but also every subject showed such an attenuation.

At very low spatial frequencies, sensitivity increased again (see at $0.04 \mathrm{c} /{ }^{\circ}$ ). Such a characteristic has already been described for the pigmented rat (Harnois et al., 1984). The increase at very low spatial frequencies might be explained by the fact that these gratings could be detecied as edges and, obviously, the sensitivity to edges or local flux of luminance might be different from the sensitivity to spatial frequency. These variations of the CSF of the albino rat at low spatial frequencies had previously been passed over, at least in part, which can easily happen since the whole curve is shorter than half a log unit! One has to explore very close frequencies to detect the differences.

Up to the sensitivity peak (at $0.1 \mathrm{c} /$ ), sensitivity decreases and the estimated cut-off is $0.48 \mathrm{c}^{\circ}$ for the albino rat. This value fits with the previously mentioned behavioral estimations, between 0.35 and $0.43 \mathrm{c} /{ }^{\circ}$ (Birch \& Jacobs, 1979; Muñoz Tedó et al., 1992). A similar difference is observed between the behavioral and the VEP estimations of the cutoff in the pigmented rat. The behavioral estimations are between 1.0 and $1.2 \mathrm{c} /$ (Birch \& Jacobs; Legg, 1984) and the VEP values are between 1.2 and $1.8 \mathrm{c} /$ (Harnois et al., 1984; Silveira et al., 1987). The relationship between VEP and psychophysical contrast sensitivity thresholds has been established in human, monkey, and cat (Maffei, 1978). It seems that this is also the case for rats. This exciting possibility could be extended to other absolute thresholds, as suggested by previous work on luminance threshold in rodents in the laboratory (Herreros de Tejada, Muñoz Tedó \& Costi, 1997; Muñoz Tedó et al., 1994). In all cases, psychophysics lead to slightly lower threshold values which could be explained by the fact that behavioral measurements are mediated by a learning task, and this might somehow interfere with the performance at stimulus values close to the detectable limit.

The comparison of albino and pigmented rats' CSF determined electrophysiologically (see Figure 3) under similar experimental conditions also shows that, as has already been described, albino subjects suffer sensitivity loss at high spatial frequencies, compared to pigmented subjects of the same species. The characteristics of the CSF, however, remain unaffected. Nonetheless, a general decrease of the sensitivity values is observed. The peak value obtained in this work for the Sprague-Dawley rat is approximately 20. The peak of sensitivity value obtained by Silveira and co-workers (1987) for the Lister hooded rats is about 29. The general reduction of spatial contrast sensitivity in albino subjects is already well documented (Birch \& Jacobs, 1979; Witson, Mets, Nagy, \& Ferrera, 1988) and these data confirm it. Such a reduction of sensitivity is related to the anatomical and physiological differences described in the visual system of albino subjects (Drager \& Olsen, 1980; Guillery, 1974; Lund, 1965), as well as to the reduction of the optical quality of the retinal image, caused by the absence of pigment, both in the iris and the epithelium, that blur the image.

Summing up, the results presented here show the whole CSF of the albino rat. This electrophysiologically determined function shows the characteristics described for the CSF of the pigmented rat (Legg, 1984; Silveira et al., 1987) and other mammals (Ulrich, Essock, \& Lehmkuhle, 1981). The estimated cut-off is $0.48 \mathrm{c}^{\circ}$, which is slightly higher than the behavioral estimation for these animats and clearly below the cut-off for the pigmented rat.

\section{References}

Balkema, G.W. (1988). Elevated dark-adapted thresholds in albino rodents. Investigative Ophthalmology and Visual Science, 29 , 544-549.

Birch, D., \& Jacobs, G.H. (1979). Spatial contrast sensitivity in albino and pigmented rats. Vision Research, 19, 933-937.

Boyes, W.K., \& Dyer, R.S. (1983). Pattern reversal visual evoked potentials in awake rats. Brain Research Bulletin, 10, 817-823.

Drager, U.C., \& Ossen, J.F. (1980). Origins of crossed and uncrossed retinal projections in pigmented and albino mice. Joumal of Comparative Neurology, 191, 383-412.

Dyer, R.S., \& Swartzwelder, S.H. (1978). Sex and strain differences in the visual evoked potentials of albino and hooded rats. Phamacology, Biochemistry and Behavior, 9, 301-306.

Guillery, R.W. (1974). Visual pathways in albinos. Scientific American, 230, 44-54.

Harnois, C., Bodis-Wolner, I., \& Onofrj, M. (1984). The effect of contrast and spatial frequency on the visual evoked potential of the hooded rat. Experimental Brain Research, 57, 1-8.

Hayes, J.M., \& Balkema, G.W. (1993). Elevated dark adapted thresholds in hypopigmented mice measured with a water maze screening apparatus. Behavior Genetics, 23, 395-403.

Herreros de Tejada, P., Green, D.G., \& Glover, M.J. (1994). Electrophysiological estimates of visual sensitivity in albino and pigmented mice. Visual Neuroscience, H, 919-925.

Herreros de Tejada, P., Muñoz Tedó, \& C., Costi, C. (1997). Behavioral estimates of absolute visual threshold in mice. Vision Reseurch, 37, 2427-2432.

Heywood, C.A., Silveira, L.C.L., \& Cowey, A. (1988). Contrast sensitivity in rats with increased or decreased numbers of retinal gyanglion cells. Experimental Brain Research, 70, 513-526.

LaVail, M.M., Nixon, R.A., \& Sidman, R.L. (1978). Genetic control of retinal ganglion cell projections. Journal of Comparative Neurology, 182, 399-422. 
Legg, C.R. (1984). Contrast sensitivity at low spatial frequencies in the hooded rat. Vision Research, 24, 159-161.

Lund, R.D. (1965) Uncrossed visual pathways of hooded and albino rats. Science, 149, 1506-1507.

Maffei, L. (1978). Spatial Frequency Channels: Neural Mechanisms. In A.C. Held, H.W. Leibowitz, \& H. Teuber (Eds.), Handbook of sensory physiology (Vol. VIII, pp. 37-66). New York: L. Springer Verlag.

Montero, V.M., Rojas, A., \& Torrealba, F. (1973). Retinotopic organization of striate and prestriate visual cortex in the albino rat. Brain Research, 53, 197-201.

Muñoz Tedó, C., Herreros de Tejada, P., \& Cañavate, A. (1992). Estudios fisiológicos y conductuales de la detección de frecuencias espaciales en roedores. Investigaciones Psicológicas, $11,83-97$.

Muñoz Tedó, C., Herreros de Tejada, P., \& Green, D.G. (1994). Behavioral estimates of absolute thresholds in rat. Visual Neuroscience, $11,1077-1082$
Sanderson, K.J., Guillery, R.W., \& Shackelford, R.M. (1974). Congenitally abnomal visual pathways in mink (Mustela vison) with reduced retinal pigment. Journal of Comparative Neurology, 154, 225-248.

Silveira, L.C.L., Heywood, C.A., \& Cowey, A. (1987). Contrast sensitivity and visual acuity of the pigmented rat determined electrophysiologically. Vision Research, 27, 1719-1731.

Ulrich, D.J., Essock, E.A., \& Lehmkuhle, S. (1981). Cross-species correspondence of spatial contrast sensitivity functions. Behavioral Brain Research, 2, 291-299.

Wilson, H. R., Mets, M.B., Nagy, S. E., \& Ferrera, V. P. (1988). Spatial frequency and orientation tuning of spatial visaal mechanisms in human albinos. Vision Research, 28, 991-999.

Received November 15, 1996 Revision received March 19, 1997 Accepted May 9, 1997 